\title{
Sum of Longest Diameters
}

National Cancer Institute

\section{Source}

National Cancer Institute. Sum of Longest Diameters. NCI Thesaurus. Code C96632.

A calculation of the aggreg ated longest diameter values. 